\title{
As Representações Sociais de Professores do Ensino Médio
}

\author{
MARIA LAURA PUGLISI BARBOSA FRANCO \\ Professora Titular do Programa de Pós-Graduação em Psicologia da Educação da \\ PUC/SP Pesquisadora Sênior da Fundação Carlos Chagas \\ mfranco@fcc.org.br \\ YEDA MARIA DA COSTA LIMA VARLOTTA \\ Doutora em Psicologia da Educação pela PUC/SP \\ piex@zas.com.br
}

\begin{abstract}
Resumo
Este trabalho tem por objetivo caracterizar as Representações Sociais - RS que professores do Ensino Médio constroem, desenvolvem e elaboram acerca de alguns aspectos relacionados ao Espaço Público, à Gestão Escolar e à Prática Pedagógica. Para tal foram contatados 875 professores que lecionam no Ensino Médio da rede estadual de São Paulo, incluindo o Município, a Grande São Paulo e o interior do Estado. Os professores responderam a um questionário contendo questões "abertas" e "fechadas". As respostas foram submetidas a uma cuidadosa análise de conteúdo para a identificação de seus significados e sentidos. Entre outros, os resultados indicam uma representação consolidada da escola pública como um espaço de carências nunca supridas. Esta representação, ancorada em vários elementos do que falta ter, do que falta fazer acaba tendo uma função negativa, sempre presente, do não reconhecimento de ações importantes para a melhoria das condições do ensino, consolidando uma visão de contínuo descaso do poder público para com a educação o que repercute em atitudes e comportamentos na escola e na sala de aula.
\end{abstract}

Palavras-chave: representações sociais, pesquisa qualitativa, ensino médio, análise de conteúdo.

\section{Resumen}

El objetivo de este trabajo es caracterizar las Representaciones Sociales - RS que profesores de la Enseñanza Media construyen, desenvuelven y elaboran sobre algunos aspectos relacionados con el Espacio Publico, la Gestión Escolar y con la Práctica Pedagógica. Para eso, se entrevistaron 875 profesores que leccionan en la Enseñanza Media de la red estadual de San Pablo, incluyendo el Municipio, la Grande San Pablo y el interior del Estado. Los profesores respondieron a un cuestionario que incluía preguntas "abiertas" y "cerradas". Las respuestas fueron submetidas a un análisis cuidadoso sobre el contenido para la identificación de sus significados y sentidos. Entre otros, los resultados indican una representación consolidada de la escuela pública como un espacio de necesidades nunca satisfechas. Esta representación, fundamentada en varios elementos de lo que falta 
tener y de lo que falta hacer, acaba por tener una función negativa, presente siempre, del no reconocimiento de las acciones importantes para la mejoria de las condiciones de la enseñanza, fortaleciendo una visión de contínua omisión del poder público con la educación, repercutiendo en actitudes y comportamientos en la escuela y en la clase.

Palabras-clave: representaciones sociales, investigación cualitativa, enseñanza media, análisis de contenido.

\begin{abstract}
This paper aims at characterizing the Social Representations - SR - that middle school teachers build, develop and elaborate concerning aspects related to Public Space, School Administration and Pedagogical Practice. The subjects of this study were 875 state middle school teachers in the state of São Paulo, covering its municipality, Greater São Paulo as well as the inland. Teachers completed a questionnaire with "open" and "closed" questions. Answers were submitted to careful content analysis to identify underlying meanings. Results indicate, among other findings, that public school is represented as a space where needs are never met. This representation, anchored on various elements as to what is still missing, what still needs to be done, carries an ever-present negative function of not recognizing important actions taken to improve teaching conditions, thus consolidating an idea of continuous neglect by state authorities toward education. This, in turn, surfaces in attitudes and behavior at school and in the classroom.

Key words: social representations, qualitative research, middle school, content analysis.
\end{abstract}


O objetivo deste trabalho é caracterizar as Representações Sociais RS que professores do Ensino Médio constroem, desenvolvem e elaboram acerca de alguns aspectos relacionados ao Espaço Público, à Gestão Escolar e à Prática Pedagógica. A decisão de valorizar o estudo das RS, como categoria analítica, na área da Educação está baseada em nossa crença de que esta valorização representa um avanço, uma vez que significa efetuar um corte epistemológico que contribui para o enriquecimento e aprofundamento dos velhos e já desgastados paradigmas das Ciências Psicossociais.

Além disso, não apenas para a Educação, mas, de uma maneira geral, para a Sociedade do Conhecimento, a abordagem e realização de pesquisas sobre as RS podem ser consideradas como ingredientes indispensáveis para uma compreensão mais consubstanciada dessa Sociedade e para a aquisição de um entendimento mais científico, mais crítico e historicamente sobre o que significa conhecer e o que representa adquirir conhecimento. Conhecimento que, muitas vezes, transforma-se em um veículo de manipulação, de alienação e, que, portanto, incorpora "meias verdades", em geral divulgadas pelos mais diferentes meios de comunicação. No entanto, apesar de sua importância, enfatizada em várias ocasiões, o estudo das RS não tem sido suficientemente explorado como um valioso indicador para a compreensão da realidade social mais ampla, bem como para a tomada de decisões no âmbito das Políticas Públicas e em especial das Políticas na área da Educação.

Sabemos que as RS são elementos simbólicos que as pessoas expressam mediante o uso de palavras, silêncios e gestos. No caso do uso de palavras, recorrendo à linguagem oral ou escrita, as pessoas explicitam o que pensam, a forma como percebem esta ou aquela situação, que opinião formulam acerca de determinado fato ou objeto, que expectativas desenvolvem a respeito disto ou daquilo, e assim por diante. Essas mensagens, mediadas pela linguagem, são elaborações mentais construídas socialmente, estão necessariamente ancoradas no âmbito social e histórico da sociedade e podem ser generalizadas pela situação real e concreta dos indivíduos que as emitem.

Partimos, pois, da premissa de que as RS são elaborações construídas na dinâmica que se estabelece entre a atividade psíquica do sujeito que conhece e o objeto do conhecimento. Relação que se dá na prática social e histórica da humanidade e que se generaliza por via da linguagem. O produto pensado e falado é, portanto, fruto da atividade humana , ou seja, uma réplica interiorizada da ação. 
Nesse sentido, concordamos com Leontiev quando diz que "as Representações Sociais são comportamentos em miniatura". Por essa razão, nós lhe atribuímos uma virtude preditiva, uma vez que, segundo o que um indivíduo diz, podemos não apenas conhecer suas concepções sobre variadas questões, como também podemos deduzir sua orientação para a ação. Sendo, portanto, um indicador que se reflete na prática cotidiana, tanto de alunos quanto de professores e demais profissionais envolvidos no exercício de suas competências, devemos estar atentos e levar em conta as RS não apenas para a tomada de decisões político-educacionais como também para a melhoria da qualidade do ensino em todos os níveis. Em nosso caso, trabalhamos com os professores do Ensino Médio o que se justifica pelas observações a seguir.

Considerando o processo de transformação e de modernização em curso no País, o Ensino Médio tem um importante papel a desempenhar. Tanto nos países desenvolvidos quanto nos que lutam para superar o subdesenvolvimento, a melhoria da qualidade do Ensino Médio pode ser um poderoso fator de formação para a cidadania e de qualificação profissional. Além disso, priorizar a escolha do Ensino Médio, como tema para debate e/ou como objeto de estudo e reflexão adquire, atualmente no Brasil, redobrada pertinência, seja:

- pela sua inclusão na Educação Básica, prevista na Lei n. 9394/96 (a nova LDB) que, em uma perspectiva de universilização e de democratização de acesso a um maior número de anos de escolaridade, define a obrigatoriedade progressiva do Ensino Médio, enquanto etapa final da Educação Básica;

- por sua histórica indefinição que sempre oscilou entre uma oferta de ensino profissionalizante e geral de caráter propedêutico;

- pela mudança que está sendo prevista e implementada em relação à sua reestruturação curricular;

- pelo crescente aumento observado no que diz respeito à demanda por este nível de ensino (principalmente por parte daqueles que freqüentam as escolas públicas estaduais);

- pelo número muito pouco representativo de estudos que têm se dedicado à sua análise; e, finalmente,

- pela necessidade de verificar que tipo de jovens estão sendo formados, neste patamar de ensino, tendo em vista as exigências de um mercado de trabalho globalizado (em acelerada mutação) e, ao mesmo tempo, levando em conta a 
urgência de formar jovens conscientes, historicamente engajados com os problemas de seu tempo, dinâmicos e participativos.

\section{A PESQUISA}

Os dados relativos às RS dos professores do Ensino Médio foram coletados no bojo de uma pesquisa mais ampla e podem ser considerados como um dos desdobramentos de um Projeto de Pesquisa desenvolvido pela Fundação Carlos Chagas, em 2002.

Para tal foram contatados 875 professores de escolas públicas (incluindo capital, Grande São Paulo e interior) junto aos quais foi aplicado um questionário contendo 29 questões "fechadas" e "abertas". Dentre as "abertas" 4 foram dirigidas para a captação das RS. Estas questões foram:

- Diga o que você considera importante para a melhoria de sua prática docente.

- Para você, o que significa Projeto Pedagógico?

- Sobre a recuperação dos alunos o que você considera importante?

- O espaço abaixo está reservado para você manifestar suas opiniões acerca do Promed. Escreva quais são elas. ${ }^{1}$

A partir do material escrito pelos professores, e, tendo em vista a grande quantidade de respostas obtidas, elas foram preliminarmente submetidas ao programa computacional Alceste que possibilitou uma primeira análise léxica e lógico-estrutural de seus conteúdos. Por tratarse de RS, as respostas foram, posteriormente, agrupadas em categorias levando-se em conta o sentido lógico e semântico de seus significados na busca de eixos definidores de representações que esses professores vêm construindo, com base em suas experiências e vivências cotidianas, representações essas que, ao mesmo tempo, influenciam suas atividades, percepções, valores, julgamentos e decisões.

Finalmente, elegemos três eixos para orientar a análise e interpretação das RS que permeiam a vivência profissional desses

\footnotetext{
1 As respostas obtidas a partir desta questão não serão objeto deste trabalho, pois referem-se especificamente ao Promed.
} 
professores. São eles: a melhoria da prática docente; o projeto pedagógico da escola e a recuperação de alunos com desempenho insatisfatório.

\section{OS RESULTADOS}

\subsection{A melhoria da prática docente}

Tendo em vista que as representações são construídas e ancoradas na interação que estabelece com os demais protagonistas do contexto em que atuam, os professores incluídos na amostra desta pesquisa elaboram representações que se associam a uma imagem positiva de seu desempenho docente, revelando um esforço de constituição de identidades positivas como profissionais: "a diretora sempre me diz que eu sei fazer"; "os alunos gostam das minhas aulas"; "meus alunos aprendem"; "eu me considero uma profissional competente"; "aliás, até já ganhei uma menção honrosa e uma medalha, no final do ano passado, quando teve a formatura da $3 \underline{a}$ série".

Embora revelem uma visão de si mesmos como profissionais competentes, quando questionados sobre o que seria necessário para melhorar a prática docente, e, portanto, o ensino, apóiam-se em condições externas, assumindo representações mais amplamente presentes no cenário educacional, pela reiteração de falas que permeiam o ambiente escolar de diversas formas. $\mathrm{O}$ contraponto da representação de si como profissional competente é a idéia de que a melhoria do trabalho docente depende das condições a serem oferecidas ao professor para realizar seu trabalho. Nesse sentido, expressam necessidades, reais ou não, representadas como ausência ou falta. A representação de carências no sistema público de ensino forma um traço ambíguo nas falas dos professores, em contraposição à boa imagem de si.

O significado das faltas ou das necessidades sentidas refere-se a diversos itens, mas todos formam a reiteração de um mesmo discurso, já tão ouvido em tantas instâncias, mostrando o caráter psicossocial da cristalização de determinadas representações no cotidiano escolar. Essas carências sentidas, para que possa melhorar a qualidade do ensino, referem-se à questão salarial, às condições de exercício da profissão e de infra-estrutura escolar e, finalmente, aos próprios alunos e seus pais.

Um grupo de falas destaca a necessidade de valorização profissional: "É preciso ter salários mais dignos"; "melhores salários"; "se não houver remuneração para horas extras de planejamento, nada vai melhorar"; "deveria haver um plano decente de valorização do 
professor, tanto por parte do governo como da comunidade"; "valorização profissional, em primeiro lugar e, em seguida, um compromisso".

Valorizar, nesse sentido, também incluiria oferecer condições mais seguras de trabalho:

"A Secretaria de Educação deveria tomar providências para que pudéssemos ter mais segurança no trabalho, principalmente no período noturno, contratando seguranças... Do jeito que está, a gente acaba as aulas e vai correndo embora, sem conversar com os colegas e tentar discutir problemas para a melhoria da prática docente."

Ainda em relação às condições a serem oferecidas ao professor para realizar seu trabalho, aparecem falas sobre o sistema de funcionamento das unidades escolares, tanto no que diz respeito a sua organização quanto à existência e/ou disponibilidade real de recursos a serem utilizados. Assim, as falas sugerem um tom de reivindicação, de ausência, reforçando a idéia de que as RS elaboradas para os obstáculos à melhoria da prática docente são concebidas como fatores externos, embora no interior das instituições escolares.

As afirmações a seguir remetem à estrutura física e à organização da unidade escolar: "Deveríamos ter salas com menor número de alunos"; "[deve haver] cursos de certas disciplinas com mais freqüência, principalmente Inglês, que é esquecido sempre, embora seja uma freqüente reivindicação dos alunos"; "é muito importante aumentar o número de aulas semanais por série, porque os conteúdos são enormes; "que volte a existir seis aulas por período". Uma fala sugere investimento dos próprios professores, para se aperfeiçoar:

"Considero importante mais tempo livre nas $\mathrm{HTPCS}^{2}$, para aprofundar projetos com base em pesquisas sólidas, para discutir categorias de avaliação e diagnósticos mais profundos da realidade de ensino-aprendizagem e da realidade sociocultural dos alunos."

Outras destacam carências de recursos materiais e pedagógicos: "Deveríamos ter uma biblioteca que funcionasse bem"; "temos sala de informática, mas não funciona, vive trancada"; "[faltam] materiais que facilitem nossas aulas, como jogos, vídeos, apostilas, fitas de vídeo etc."; "espaço físico adequado, laboratório de Biologia e de Informática".

2 Horas de Trabalho Pedagógico Coletivo. 
Em um outro patamar, as RS construídas pelos professores e apontadas como empecilhos à melhoria de seu desempenho como profissionais referem-se a aspectos inter-relacionais, envolvendo outros atores. Eis algumas falas ilustrativas:

"Deveria haver um trabalho de conscientização dos alunos, familiares e comunidade sobre a importância dos estudos."

"Toda a equipe escolar, incluindo diretores, supervisores e professores, deveriam se empenhar para que isso acontecesse: participação dos pais, envolvimento da comunidade e de familiares."

"Não consigo fazer mais do que faço, com alunos indisciplinados, desinteressados, que ficam gritando, pulando nas carteiras e muitas vezes armados e agressivos, principalmente os do noturno."

Então, das respostas dos professores à questão sobre o que consideram importante para a melhoria de sua prática docente, emerge a RS do trabalho docente como dependente de condições externas, que poderia ser assim sintetizada: a prática docente depende das condições a serem oferecidas ao professor para realizar o seu trabalho.

\subsection{O Projeto Pedagógico da Escola}

Com base nas respostas dos professores à solicitação de explicitar o que significa projeto pedagógico, é possível dizer que existem dois tipos de RS.

O primeiro (embora restrito a uma minoria) emerge como uma representação mais elaborada, possivelmente ancorada nos objetivos previstos para a implantação da Autonomia da Escola e da Gestão Escolar. Configura-se como um todo, feito coletivamente - com a participação da comunidade, dos pais, da equipe técnica e dos alunos para melhorar a qualidade do ensino. É a RS de uma ação coletiva que, além de promover a autonomia da escola, visa a identificar problemas e necessidades, elaborar objetivos e estratégias de avaliação, ou mesmo alcançar o almejado sistema de oferta de conteúdos com uma característica de interdisciplinaridade, prevista para o Ensino Médio nos Parâmetros Curriculares Nacionais.

Um segundo tipo de RS (e que se identificou na maioria dos professores contatados: $85 \%$ ) acerca do projeto pedagógico configura-se como mais restrita e, também, mais distante do que se pretende instituir, quando se fala da necessidade de a escola elaborar seu projeto pedagógico. Emergem RS de projetos desenvolvidos pelos professores e alunos no 
interior das salas de aula, às vezes entendidos como planos de ensino, acrescidos de algum tipo de atividade que envolva o aluno. A autonomia da escola e o papel autônomo da Gestão Escolar parecem ser conceitos novos, uma idéia ainda pouco assimilada na rede, historicamente limitada por uma série de regulamentações legais e com uma estrutura hierárquica, com um século de rigidez o que não teria contribuído para desenvolver práticas mais autônomas. Embora estas sejam vistas como sedutoras e apropriadas.

Fica patente, pois, que autonomia, flexibilização curricular e interdisciplinaridade são temas que merecem um esforço concentrado, especialmente dos níveis centrais da Secretaria, no sentido de rever a reorganização curricular e as regulamentações impostas "de cima para baixo" o que, em vários casos, parecem conflitar com a desejada autonomia e com a ruptura fragmentada da oferta de disciplinas e conteúdos.

Nesse sentido, dizem os professores: "projeto pedagógico é aquele que o professor faz para despertar interesse nos alunos"; "é o desenvolvimento de competências e habilidades pelos alunos"; "significa passar a teoria para a prática, porque os alunos, ao desenvolver suas tarefas, ao realizar suas atividades, aprendem muito". Ou então:

"Projeto pedagógico é aquele que consegue estimular o aluno e fazer com que ele pense não apenas nos conteúdos, mas também no que é importante para o desenvolvimento de sua cidadania."

"São projetos desenvolvidos com os alunos com o objetivo de ampliar suas capacidades e seus conhecimentos."

\subsection{A recuperação}

A recuperação dos alunos do Ensino Médio que não conseguem obter resultados satisfatórios no decorrer do ano letivo pressupõe uma discussão preliminar acerca de alguns elementos do processo de desenvolvimento da rotina da escola; dos tipos de avaliação a que são submetidos; dos critérios que orientam as decisões quanto àqueles que devem (ou não) ser recuperados; das modalidades de recuperação existentes; e, fundamentalmente, a explicitação das RS que os professores elaboram acerca desses diferentes aspectos.

Embora os professores valorizem a participação dos alunos em projetos complementares que associem, por exemplo, a "teoria e a prática", na maioria dos casos as provas, sistematicamente aplicadas aos alunos, privilegiam basicamente, senão exclusivamente, a verificação da aprendizagem dos conteúdos desenvolvidos no decorrer do ano letivo nas 
diferentes disciplinas ministradas. Portanto, são provas de avaliação de rendimento. Para aqueles que não demonstram um rendimento satisfatório nas referidas provas, e também visando à correção do fluxo escolar, são adotadas, a critério de cada escola, estratégias de recuperação. Dentre elas destacam-se a recuperação paralela - feita ao longo do ano letivo - e a recuperação nas férias.

Das respostas dos professores relativas à recuperação paralela, emergem RS que poderiam ser assim resumidas: a recuperação paralela é ótima porque é sistemática, contínua, dinâmica e, acompanhada pelo professor, apresenta bons resultados Algumas falas exemplificam as vantagens da recuperação paralela: "os alunos percebem que recebem maior atenção, por ser um número de alunos reduzido"; "os alunos se interessam e participam e, assim, aumenta sua auto-estima". E ainda:

"Os alunos fazem trabalhos práticos fora de seu horário de aulas, levando a um maior interesse pelo projeto desenvolvido no período."

"É realizada a partir das dificuldades e necessidades diagnosticadas pelo professor, que sempre procura recursos externos para a recuperação."

"É praticamente individualizada e baseada neste ou naquele ponto que o aluno precisa recuperar."

Quanto à recuperação levada a efeito durante o período das férias escolares, embora alguns professores expressem alguns vagos pontos positivos - como "contribui para que não ocorra defasagem idade-série"; "é uma nova oportunidade de aprendizagem" - a maioria das representações sobre essa estratégia de recuperação expressa negação, rejeição, alegando-se sua improdutividade, por diferentes motivos.

Na visão dos professores, a recuperação nas férias não surtiria efeito por sua curta duração ou por ser desconectada do trabalho feito durante o ano letivo: "Não vejo aspecto positivo pelo curto período usado para a recuperação das deficiências de conteúdos"; "não há recuperação alguma de conteúdo em espaço de tempo tão curto"; "não há melhoria da aprendizagem"; "em três semanas não se recupera um semestre ou um ano, o tempo é curto". Ou: "os projetos desenvolvidos não são compatíveis com o conteúdo trabalhado"; "os alunos são avaliados por professores que não conhecem sua realidade, porque não trabalharam com eles durante o ano letivo".

Por outro lado, a recuperação de férias teria ainda um efeito nefasto em geral, porque "acaba desmotivando aqueles outros que se 
esforçam durante todo o ano" e, também, por seu aparente caráter de aprovação necessária:

"Os alunos percebem que não precisam se preocupar durante o ano letivo, já que recupera durante apenas 30 dias, nas férias."

"Os alunos se acomodam durante o ano porque sabem que, nas férias, existe a possibilidade de recuperar o tempo perdido; isso atrapalha o rendimento durante o ano todo - em outubro, começam a faltar."

“Como os alunos já sabem de antemão que, se freqüentarem o mês de férias na recuperação, serão aprovados, não se preocupam muito em estudar durante todo o ano letivo e isso deixa os professores sem perspectiva."

“O aluno é aprovado, isso é muito bom, mas sem o conhecimento necessário. Esse aluno terá muita dificuldade em acompanhar as aulas da série seguinte e, muito menos, terá condições de entrar na faculdade ou de arrumar emprego."

Resumidamente, pois, a RS acerca da recuperação feita ao longo do ano letivo é altamente positiva - por sua efetividade - e as RS sobre recuperação nas férias são bastante negativas, por não beneficiar os alunos.

\section{APRECIAÇÃO}

Não é desprezível o fato de que, embora reconhecendo os insumos recebidos pelas escolas e os esforços para a formação continuada de professores, estes tenham consolidada a representação social da escola pública como um espaço de carências nunca supridas. Esta representação, ancorada em vários elementos do que falta ter, do que falta fazer, como se mostrou anteriormente, acaba tendo uma função de negação sempre presente, de não reconhecimento de ações importantes para a melhoria das condições do ensino, consolidando uma visão de contínuo descaso do poder público para com a educação, o que repercute em atitudes e comportamentos na escola e na sala de aula. Com essa representação cristalizada, é como se nada, nunca, pudesse ser bom ou relativamente bom, o que gera uma atmosfera pouco receptiva a inovações, mesmo que interessantes e necessárias. Por isso, o empenho para mudar essa cultura instalada é condição para se ter uma participação mais consciente e crítica (e não reagente e destrutiva). Este é um espaço fora do âmbito da racionalidade linear: não basta informar, divulgar. É preciso mobilizar, fazer acreditar, envolver, provocar a participação efetiva, criando 
condições para uma crítica ancorada em maior objetividade e não no senso-comum. A desinformação, aqui, tem papel deletério e, por essa razão, é imperativo criar caminhos de comunicação mais transparentes, mais ágeis, mais expostos, para reverter esse quadro em que a imagem da escola pública é sempre algo irremediavelmente feio e ruim. As práticas pedagógicas contaminam-se com essas imagens, gerando modos pouco eficazes de lidar com os problemas reais, concretamente instalados na sociedade, e que se refletem na sala de aula.

\section{REFERÊNCIAS BIBLIOGRÁFICAS}

LEONTIEV, A. O desenvolvimento do Psiquismo. Lisboa: Livros Horizonte, 1982.

PROMED. Relatório Final, Secretaria de Educação do Estado de São Paulo, 2002.

Recebido em: janeiro 2004 Aprovado para publicação em: junho 2004 